\title{
Innovating a way out
}

\author{
The ongoing European Union fiscal crisis has taken its toll on research and innovation across several \\ member states. A number of initiatives aim to boost technological innovation as a tool for increasing wealth.
}

The importance of technological innovation as a tool for wealth development is indisputable. In fact, the 'Europe 2020' strategy is heavily based on 'smart growth' - a term referring to education, research and innovation (R\&I), and information and communication technologies - as well as on the encouragement of scientific and academic excellence. This is directly connected to sustainable and inclusive growth, which should lead to increases in competitiveness and lower unemployment rates ${ }^{1}$. The hard reality of the debt crisis, however, and the perception of R\&I as a possible way out of it, forced EU countries to look seriously into protecting public R\&I activities, attracting private funds and investing further in this direction.

Despite the political commitment for a European standard of investing 3\% of the gross domestic product (GDP) in research and education ${ }^{2}$, as announced in the 2002 Lisbon treaty, only 6 member states achieved that target in $2013^{3}$. At present, less than $2 \%$ of Europe's wealth is spent on research, and securing funding for R\&I policies is increasingly challenging. The EU member states most severely hit by the crisis have been forced to decrease their R\&I public budgets in line with overall budgetary cuts; Poland, Spain, Italy, and the Netherlands among others saw an overall decrease in public funding of about $10 \%$ between 2008 and 2012.

Instead, countries that lead in innovation, such as Sweden, Germany and Denmark, increased their public R\&I budgets, approaching or even surpassing the 3\% EU standard. These countries remain committed to their long-standing goal of innovationbased economic growth, putting in place well-functioning measures for its protection, and successfully harnessing the potential of globalization for the exploitation of new markets.

The UK, also a leader in innovation, opted for increasing cuts over the years, and at present allocates $1.72 \%$ of its GDP to $R \& I^{5}$. Yet the country benefits from a strong scientific community combined with longstanding and stable policies that stimulate innovation and entrepreneurship (the country ranks eighth worldwide in terms of ease of doing business ${ }^{6}$ ). Richard Murray

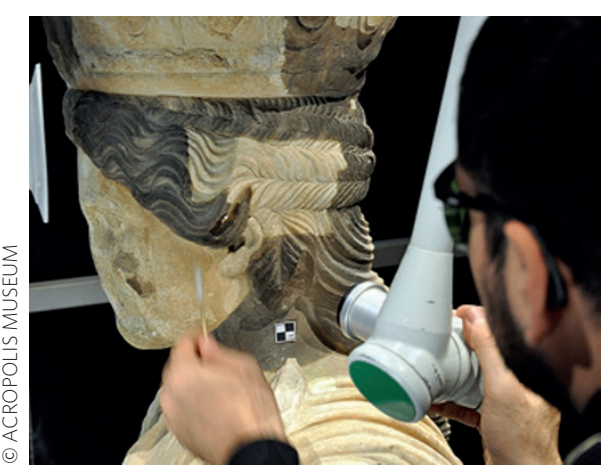

One of the Caryatids in the Acropolis museum, getting a facelift using a dual laser system developed for the project by the Acropolis Museum and the Institute of Electronic Structure and Laser at the Foundation for Research and Technology in Crete.

from Innovate UK, a dedicated innovation agency, explains in an Interview on page 851 the agency's role in actively identifying and nurturing new technological areas with high potential for national wealth growth. In this respect, the Quantum Technologies Programme stands out as an ambitious endeavour that brings together universities and private companies of various sizes, supported by a mixture of public and private funds. Regardless of whether a quantum computer will eventually be built, the collaborations that will be forged between the different partners and the highly skilled personnel that they attract are expected to self-sustain the field for much longer than the duration of the programme.

For countries with a less developed innovation culture and with economies that are more reliant on traditional industries, financing innovation is not straightforward ${ }^{7}$. For Greece, the persistent austerity makes it even harder ${ }^{8}$ : its investment in research and development is still pinned below $1 \%\left(0.69 \%\right.$ in $\left.2012^{5}\right)$. Admittedly, efforts to nurture the transition to a knowledgedriven economy were put in place before the sovereign debt crisis, and in many cases they were successful: for example, laserbased technology developed at the Institute of Electronic Structure and Laser of the Foundation for Research and TechnologyHellas of Crete in the late 1990s was recently employed in collaboration with the
Acropolis Museum to clean the surface of the Caryatids (the life-size marble maidens serving as columns for the Erechtheion, one of the Acropolis temples; see image) from pollution and acid-rain residues ${ }^{9}$. Nevertheless, the continuation of austerity is threatening to reverse the positive pre-crisis trends that were observed as the research community was growing in number and status. The general consensus, for countries with similar characteristics, is that innovation policies and funding possibilities need to be revisited. The Greek Alternate Minister for Research and Innovation, Costas Fotakis plans to do exactly that. In an Interview on page 853 he asserts that his efforts to promote innovation and entrepreneurship will target two crucial problems: the excessive bureaucracy, and the lack of a reliable legal framework for attracting funds and nurturing entrepreneurial mentality.

The hard truth is, however, that most countries hit by the crisis are facing a problem much bigger than the austerity cuts. Greece, Portugal and Spain have seen the migration rates of their skilled labour force skyrocket in the past few years. Attempts to attract and retain scientists have been put in place in several countries - the Investigator FCT-IF programme in Portugal, and the Ramon y Cajal and Juan de la Cierva initiatives in Spain being prime examples but these remain a drop in the ocean.

The current situation in Europe resembles the eternal chicken-and-egg question. Europe has a strong research presence but has not managed to fully capitalize on it yet. If innovation is one of the answers to the EU financial crisis and to prosperity, what does come first: the established R\&I ecosystem to attract the right people and nurture promising initiatives, or the highly skilled personnel that can lay the foundations for smart growth?
References
1. http://go.nature.com $/ 5 \mathrm{LxBeC}$
2. http://go.nature.com/9bXjFZ
http://go.nature.com/GYTHZX
. http://go.nature.com/9wiaQ7
5. http://go.nature.com/x3OHil
6. http://go.nature.com/b25kGe
7. http://go.nature.com/7geT4q
8. http://www.nature.com/nmat/focus/greece/index.html
9. http://go.nature.com/TQuK7T 